\title{
Using multi-criteria analysis to select an energy source
}

\author{
Oleg Koltun ${ }^{1}$, Galina Malykha, ${ }^{2,}$, and Alexander Pavlov ${ }^{1}$ \\ ${ }^{1}$ All-Russian Research Institute for Nuclear Power Plant Operation (JSC "VNIIAES") Ferganskaya, \\ 25, 109507, Moscow, Russia \\ ${ }^{2}$ Moscow State University of Civil Engineering (National Research University), Yaroslavskoye \\ Shosse, 26, 129337, Moscow, Russia.
}

\begin{abstract}
Multi-criteria analysis is widely used to solve various technical and economic problems. There are a large number of applications of multicriteria analysis. Methods for evaluating the total set of criteria have been investigated. However, the selection of criteria for various specific tasks remains the prerogative of specialists in the relevant branches. The goal of this study was to implement a multi-criteria analysis for assessing the potential of renewable energy sources' competitiveness. Renewable energy sources also include a closed nuclear fuel cycle based on fast-neutron reactors. The advantage of such cycle is the reproduction of nuclear fuel in the same or even greater quantity than it was used. At the same time, uranium isotopes are involved in the cycle, which are waste in conventional nuclear generation. The disadvantage of a nuclear fuel cycle is an output of hazardous waste and a complex technology for its processing. This task is a strategic one, and economic reason is not sufficient in this case. A structure of criteria for strategic decision making was compiled, and eight groups of main criteria were created. An expert analysis of the criteria was carried out and their relative significance was determined. Results. The significance of economic, environmental, technological and safety criteria is revealed. The formulae for criteria normalizing to apply the integration were proposed. Preliminary multicriteria analysis has shown that a closed nuclear fuel cycle can compete with renewable energy sources such as wind and solar power plants.
\end{abstract}

\section{Introduction}

The decision on power plants building or renovation has an impact on various aspects of social life. Therefore, in power construction, we must make such decisions with a large number of influence factors. These include economic, energy, environmental, social, and other factors. This is especially true when we make decisions on using renewable energy sources compared to traditional ones.

The objective of this study was to implement the Multi-Criteria Decision Analysis (MCDA) to evaluate the potential of electric generation competitiveness. However, it has been a challenge for the decision maker to choose the optimal planning option considering

\footnotetext{
*Corresponding author: malycha@mail.ru
} 
the multiple conflicting criteria [1]. There are a number of successful applications of MCDA in various branches and countries. It was utilized for multi-criteria ranking to determine the optimal hybrid technology combination of mini-grid power systems [2]. The scalarization method and the Analytic Hierarchy Process (AHP) method can be employed to choose one of possible solutions for ceiling in a public building [3]. It provides a structure for applying MCDA in a multi-actor, multi-level context. Competence-based Multi Criteria Analysis (COMCA) was applied in a study with the aim to assess solutions for the main bottleneck of the railway network [4].

Multiple qualitative and quantitative decision criteria were included in the developed GIS-MCDA. A GIS-MCDA framework was developed to produce the agricultural land suitability maps for irrigation with reclaimed water [5]. Up to 45 economic, technological, environmental, and social criteria were taken into account for selection power plant sites [6].

The mathematical part of the MCDA has been extensively researched. The coordinate descent methodology [7], methods of fuzzy set theory [8], of artificial neural networks [9], and solutions under uncertainty [10] have been studied. However, the selection of criteria for various specific tasks remains the prerogative of specialists in the relevant branches. The mathematical tools should be based on a set of criteria that is a feature of the task.

\section{Materials and methods}

Some types of nuclear energy can also be considered a renewable energy source [13]. This is due to the use of fast-neutron reactors (FNR) with a sodium coolant. Fast neutrons convert in these reactors the widespread isotope of uranium ${ }^{238} \mathrm{U}$ into nuclear fuel plutonium ${ }^{239} \mathrm{Pu}$, which is not found in nature. In addition plutonium is produced even more than the initial load of nuclear fuel. ISO 13602-1:2002 [14] defines a renewable resource as "a natural resource for which the ratio of the creation of a natural resource to the release of that resource from nature into the technosphere is equal to or greater than one".

Such reactors are created in Russia, France, and Japan: the Phénix in France, Monju in Japan, and the BN-600 in Russia. The thermal-neutron (or "slow"-neutron) reactors also produce plutonium, but much less than FNR. The largest FNR "BN-1200" is being designed in Russia [16]. It can become the basis of a closed nuclear fuel cycle.

Some papers attempt to compare the economic characteristics of fast-neutron reactors with other types of generation. They determine the impact of electrical load and of the discount rate on economic performance [17], the influence of flow amount and type of coolant, of neutron density and temperature of shells [18]. Genetic algorithms are used to optimize the parameters of the reactor core [19]. The relative efficiency of nuclear and thermal power plants was also compared [20]. Unlike other types of renewable energy sources (exclude geothermal energy), waste from nuclear power plants is dangerous and radioactive.

Therefore, the use of each type of resource has both positive and negative sides. For a comprehensive study of the advantages and disadvantages of various energy sources, a multi-criteria analysis method was used. Methods for determining the integral criterion are widely known and are not investigated here. These include Pareto optimization, scalar ranking, summation taking into account the weight of individual criteria, the method of analytic hierarchy process (AHP), etc. However, the main difficulty is the selection of significant criteria. Thus, the international INPRO-program (International Project on Innovative Nuclear Reactors and Fuel Cycles) has more than 170 criteria that can hardly be evaluated by a single specialist [21-22].

A set of criteria for solution's estimate must satisfy certain properties [23]. The full life cycle of the object must be considered. The criteria must be objectively and unambiguously 
understood by experts and decision-makers. Multiple criteria should be combined into some groups that are similar and that also allow consideration within these groups. The set of criteria should not be redundant. The criteria should be orthogonal, that is, not repeated in nature. Qualitatively evaluated criteria should be translated into a numerical form that allows collapsing the criteria into an integral indicator.

All compared generation options must be correctly compared. If the comparison is not based on specific indicators, the power plant capacity should be the same. The energy consumption schedule should be the same, and in the case of heat or freshwater generation, the resource allocation schedule should be the same. Security must be provided according to the same requirements. Prices for materials, structures, and fuel must be set at the same time. It is necessary to take into account the cost of delivering fuel and materials. By construction we must take into account the costs of organizing construction and creating infrastructure, investment risks and contract risks.

If the different power plant projects are compared on the same site, the same geological, hydrological, and seismic conditions are taken into account. If a full comparison is not possible, you must consider compensating costs to account for additional factors.

In order to assess the significance of the criteria, a questioning by a group of experts was conducted. The several dozen experts included specialists in energy, construction, economy, and ecology who had an understanding of the problems of energy development. In addition, some persons who aren't relation to the energy sector were involved. This group was modeling the public attitude to the problems of ecology and energy.

The expert analysis was carried out in two stages. At the first stage, the expert's attitude to the generalizing criteria without sub-criteria and with minimal explanations of the substance of the issues was clarified. The preliminary set of such criteria was as follows: economic indicators, main technical specifications, indicators of sustainable energy development, criteria for promising energy development, safety and reliability indicators, indicators of technology maturity, environmental indicators, social, political and institutional criteria. The binary structure of the criteria system is shown in the figure 1.

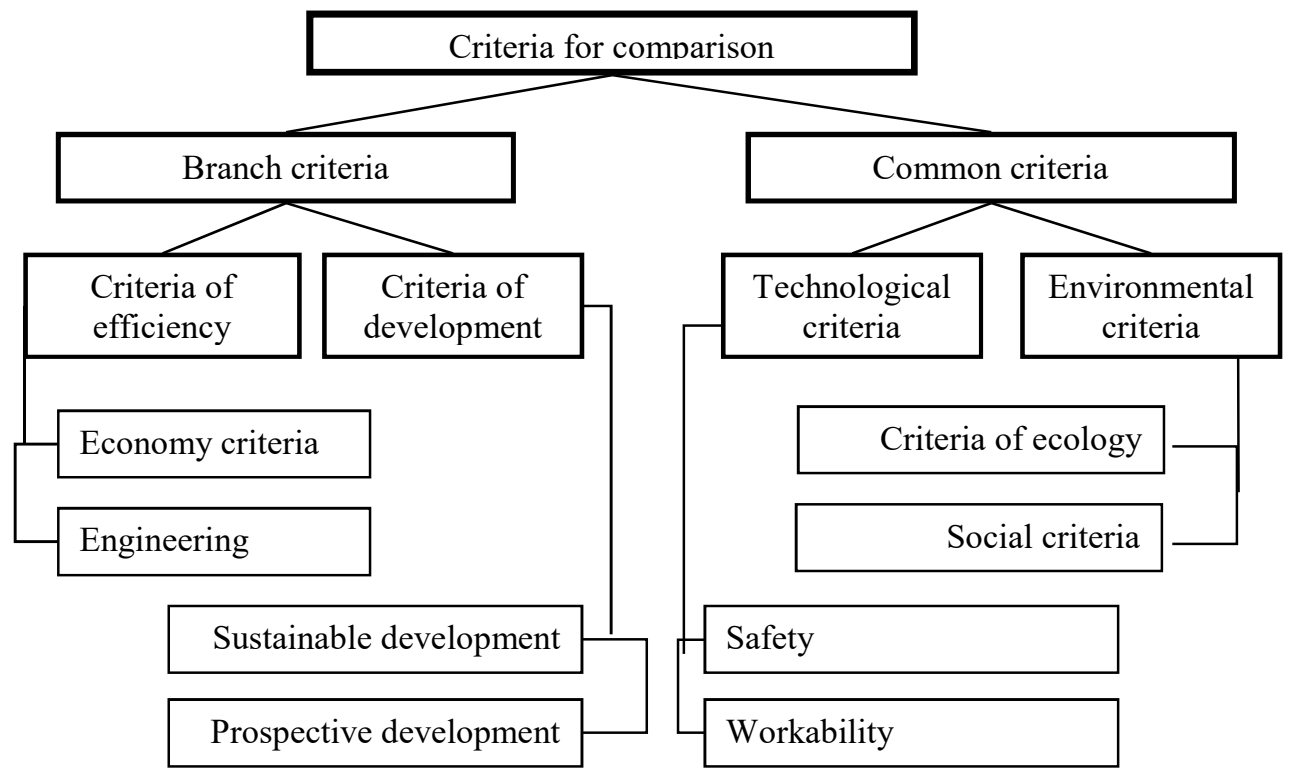

Fig. 1. Framework of the criteria system.

At the second stage of the analysis, the value of particular criteria was evaluated. Experts could also add their own criteria that were not specified in the proposed list. No 
expert has entered any additional criteria, so the proposed set of criteria can be considered exhaustive. Some criteria received a very small relative weight (less than one percent), so they could be removed from the list.

At the third stage of the analysis, all indicators were normalized. It was taken into account that some criteria have a positive effect when increasing the numeric value, while others have a positive effect when decreasing the numeric value. For a criterion that increases with increasing value, the following normalization equation is applied:

$$
k_{i}=\frac{C \cdot x_{i}}{1+C \cdot x_{i}},
$$

with:

$k_{i}=$ a normalized criterion;

$\mathrm{C}=$ a normalizing factor;

$x_{i}=$ an initial absolute value of the criterion.

When $x_{i}$ is in the range $0<x_{i}<\infty$, the value of the normalized criterion changes from 0 to 1. This formula can be used for discounted profit, power generation, efficiency, etc. On the contrary, for a criterion that decreases with increasing value, the inverse equation is used:

$$
k_{i}=\frac{1}{1+C \cdot x_{i}} .
$$

The value of the normalized criterion changes from 1 to 0 . This formula can be used for discounted costs, the cost of energy production, material resource consumption, construction period, etc. If the indicator values can take negative values, the formulae for increasing or decreasing criteria will take the following form:

$$
\begin{gathered}
k_{i}=\frac{a^{x_{i}}}{a^{x_{i}}+1}, \text { and } \\
k_{i}=\frac{1}{a^{x_{i}}+1},
\end{gathered}
$$

where $a$ is base of degree greater than one.

For qualitative criteria that do not have an exact quantitative assessment, concepts of fuzzy set theory, for example, the desire function of the Harrington type can be used [24]. Thus, when dividing the target range from 0 to 1 into five sub-ranges, the expert assessment can be indicated as follows:"very bad" - 0.1,"bad" - 0.3,"satisfactory" - 0.5,"good"- 0.7, and "very good" - 0.9. The values 0 and 1 are reserved for exceptional cases.

\section{Results}

As a result of the first stage of the expert survey, the following results were obtained for evaluating groups of criteria:

- economic indicators $-31.0 \%$;

- technical specifications - $10.0 \%$;

- indicators of sustainable energy development $-8.2 \%$;

- criteria for promising energy development $-10.6 \%$;

- $\quad$ safety and reliability indicators $-21.6 \%$;

- technology maturity $-7.4 \%$;

- environmental indicators $-7.0 \%$; 
- social, political and institutional criteria $-4.2 \%$.

The relative weight of criteria groups is shown in the figure 2 .

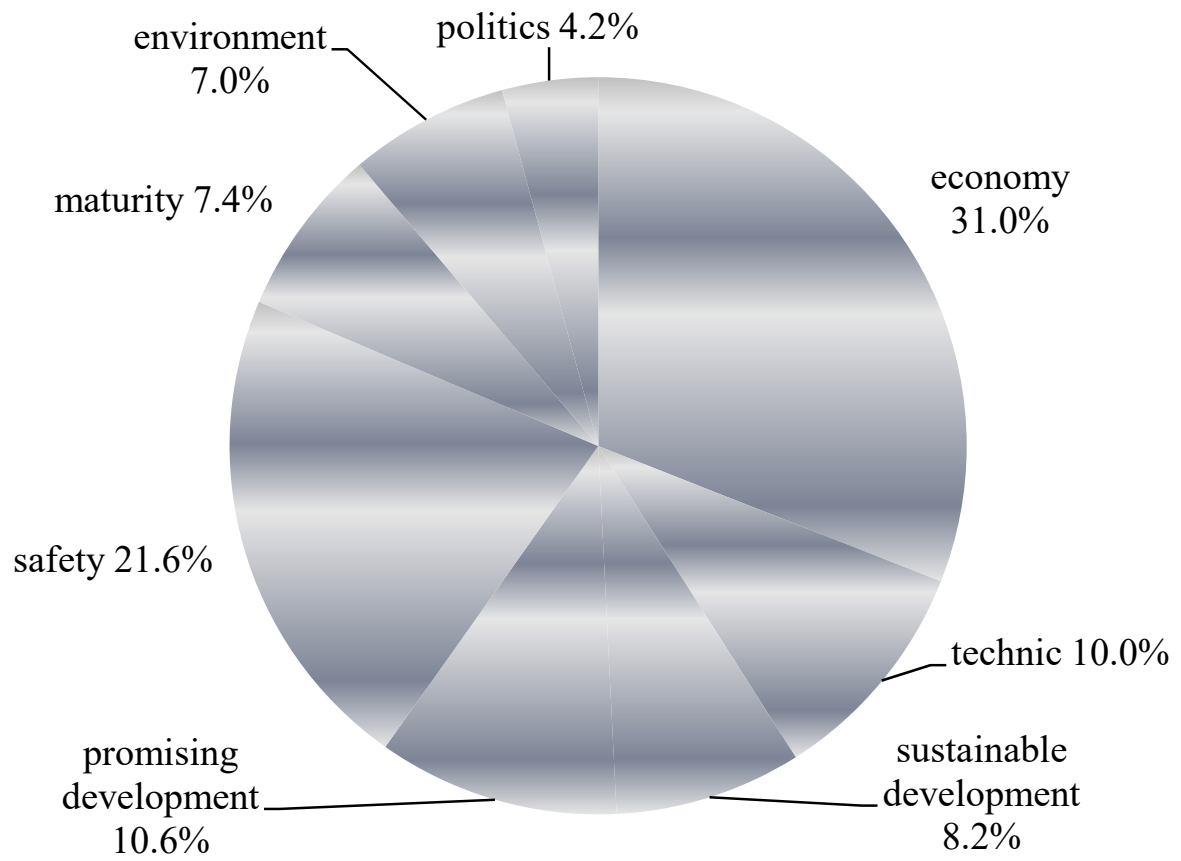

Fig. 2. The relative weight of criteria groups.

As a result of the research, the following criteria are proposed for evaluating options for developing energy sources (table 1):

Table 1. Groups and criteria

\begin{tabular}{|l|l|}
\hline \multicolumn{1}{|c|}{ Criteria groups } & \multicolumn{1}{c|}{ Criteria } \\
\hline Economic indicators & $\begin{array}{l}\text { Return on capital investment index, average cost of electricity, unit } \\
\text { discounted costs (LCOE), payback period for capital investments }\end{array}$ \\
\hline Technical specifications & $\begin{array}{l}\text { The life of the unit, a single power plant, the construction period of the } \\
\text { installation, the availability to bear the load range of the maneuvering } \\
\text { capacity, coefficient of performance, specific consumption of resources } \\
\text { for production, labor productivity }\end{array}$ \\
\hline $\begin{array}{l}\text { Sustainable energy } \\
\text { development }\end{array}$ & $\begin{array}{l}\text { Dependence on seasonal and daily climatic conditions, fuel efficiency, } \\
\text { fuel reproduction coefficient }\end{array}$ \\
\hline $\begin{array}{l}\text { Promising energy } \\
\text { development }\end{array}$ & $\begin{array}{l}\text { Export potential, dependence on import supplies, multi-purpose use, } \\
\text { dependence on seismic conditions of the site }\end{array}$ \\
\hline Safety and reliability & $\begin{array}{l}\text { The probability of an accident, the consequences of severe accidents, the } \\
\text { passivity of security systems, the number of security barriers, the flow of } \\
\text { failures, and autonomy }\end{array}$ \\
\hline Technology maturity & $\begin{array}{l}\text { Completion of R\&D, preparedness of equipment production, readiness } \\
\text { of waste processing and disposal technology }\end{array}$ \\
\hline Environmental indicators & $\begin{array}{l}\text { The amount and scarcity of natural consumed resources, the amount of } \\
\text { waste and hazard level of waste }\end{array}$ \\
\hline $\begin{array}{l}\text { Social, political and } \\
\text { institutional criteria }\end{array}$ & $\begin{array}{l}\text { Public attitude, legal maintenance, non-proliferation of dangerous } \\
\text { technologies }\end{array}$ \\
\hline
\end{tabular}


A preliminary analysis based on the considered criteria showed that a closed nuclear fuel cycle can compete with renewable sources such as wind and solar power plants. Detailed consideration of alternatives is not a task of this article and can be considered in future. However, we note that the parameters of solar and wind power generation due to the low capacity factor should not be determined by for the installed power, but by the generated energy. Moreover, due to the low availability factor, the alternatives with solar and wind power plants must be accompanied by the commissioning of conventional power plants with significant capacity.

\section{Conclusion}

This study established the importance of using both knowledge-based and data-driven criteria and sub-criteria in the decision framework. However, the received results reflect the current state of the technology and economy for considered types of generation, as well as the attitude of modern society to them. In the future, it is necessary to check the obtained results using multi-criteria analysis with obtained ratios. The ratio of criteria may also change over time.

\section{References}

1. G. Celli, N. Chowdhury, F. Pilo, G. G. Soma, M. Troncia, I. M. Gianinoni, Electric Power Systems Research, 164, 103-111 (2018). https://doi.org/10.1016/j.epsr.2018.07.017.

2. B. E. K.Nsafon, H. M. Butu, A. B. Owolabi, J. W. Roh, D. Suh, J.-S. Huh, Sustainable Energy Technologies and Assessments, 37, 100628 (2020). https://doi.org/10.1016/j.seta.2020.100628.

3. E. Szafranko, Materials Today: Proceedings, 19(5), 1945-1948 (2019). https://doi.org/10.1016/j.matpr.2019.07.047.

4. G. Boveldt, K.V. Raemdonck, C. Macharis, Transport Policy, 66, 30-39 (2018). doi.org/10.1016/j.tranpol.2018.03.002.

5. M. Paul, M. Negahban-Azar, A. Shirmohammadi, H. Montas, Agricultural Water Management, 231, 105987 (2019). https://doi.org/10.1016/j.agwat.2019.105987.

6. Study of Potential Sites for the Deployment of New Nuclear Plants in the United States. (U.S. Department of Energy, 2002).

7. J. H. Park, M. S. Khan, M. Lee, Journal of Natural Gas Science and Engineering, 27, Part 1, 32-41 (2015). https://doi.org/10.1016/j.jngse.2014.10.014.

8. D.-Y. Choi, K.-W. Oh, Fuzzy Sets and Systems, 114, 89-102 (2000).

9. C. Wong, Z.X. Guo, S.Y.S. Leung, Woodhead Publishing Series: Optimizing Decision Making in the Apparel Supply Chain Using Artificial Intelligence (2013). https://doi.org/10.1533/9780857097842.41.

10. S. Mokhtari, K. Madani, N.-B. Chang, World Environmental and Water Resource Congress: Crossing Boundaries, 2329-2348 (2012).

11. Key World Energy Statistics. (International Energy Agency, 2019).

12. J. Jurasz, F.A. Canales, A. Kies, M. Guezgouz, A. Beluco, Solar Energy, 195, 703-724 (2020).

13. UN Documents: Our Common Future, chapter 7: (Energy, 2007).URL = http://www.un-documents.net/ocf-07.htm 
14. ISO 13602-1:2002. Technical energy systems - Methods for analysis - Part 1: General (2002).

15. M. Joyce, Nuclear Engineering: A Conceptual Introduction to Nuclear Power (2018). https://doi.org/10.1016/B978-0-08-100962-8.00011-1.

16. D.V.Paramonov, E.D.Paramonova, Handbook of Generation IV Nuclear Reactors, 2016, 309-333 (2016). https://doi.org/10.1016/B978-0-08-100149-3.00012-4.

17. K. Mukaida, A. Katoh, H. Shiotani, H. Hayafune, K. Ono, Nuclear Engineering and Design, 324, 35-44 (2017). https://doi.org/10.1016/j.nucengdes.2017.08.011.

18. A.-D. Pérez-Valseca, S. Quezada-García, A.-M. Gómez-Torres, A. VázquezRodríguez, G. Espinosa-Paredes, Case Studies in Thermal Engineering, 16, 100556 (2019). https://doi.org/10.1016/j.csite.2019.100556.

19. K. Zeng, N. E. Stauff, J. Hou, T. K. Kim, Progress in Nuclear Energy, 120, 103184 (2020). https://doi.org/10.1016/j.pnucene.2019.103184.

20. T.V. Malinina, S.D. Chishko, St. Petersburg State Polytechnical University Journal, 10(1), 80-89 (2017). DOI 10.18721/JE.10107.

21. Framework for assessing dynamic nuclear energy systems for sustainability. Final report of the INPRO collaborative project on global architectures of innovative nuclear energy systems with thermal and fast reactors and a closed nuclear fuel cycle. (IAEA Nuclear Energy Series NP-T-1.14, 2013).

22. A.F. Egorov, V.V. Korobeinikov, Issues of nuclear science and technology. Series: Nuclear reactor constants, 2(2:1), 1-14 (2017).

23. A. Salado, R. Nilchiani, IEEE Transactions on Systems, Man and Cybernetics: Systems, 47(3), 1-11 (2016). DOI 10.1109/TSMC.2015.2502953.

24. D.-H. Lee, I.-J. Jeong, K.-J. Kim, Quality and Reliability Engineering International, 34(3), 360-376 (2018). DOI: 10.1002/qre.2258. 